\title{
Hiccups in neurocritical care
}

Vanitha Rajagopalan, MBBS, MD, DNB, DM'; Deep Sengupta, MBBS, DNB, $\mathrm{DM}^{1}$; Keshav Goyal, MBBS, MD, DM'; Surya Kumar Dube, MBBS, MD, $\mathrm{DM}^{1}$; Ashish Bindra, MBBS, MD, DM'; Shweta Kedia, MBBS, MD, $\mathrm{MCh}^{2}$

'Department of Neuroanaesthesiology and Critical Care, Neurosciences Centre, All India Institute of Medical Sciences, New Delhi, India

${ }^{2}$ Department of Neurosurgery, Neurosciences Centre, All India Institute of Medical Sciences, New Delhi, India

\section{Care}

\section{REVIEW ARTICLE}

Received: July 26, 2020

Revised: September 17, 2020

Accepted: December 1, 2020

Corresponding Author:

Keshav Goyal, MBBS, MD, DM

Department of Neuroanaesthesiology

and Critical Care, Neurosciences

Centre, All India Institute of Medical

Sciences, 710, New Delhi 110029, India

Tel: +91-11-26594111

Fax: +91-11-26594111

E-mail: Keshavgoyalster@gmail.com

Hiccups are usually self-limiting and benign but can be distressing when they become persistent or intractable and produce significant morbidity. In the intubated patients in neurocritical care, persistent hiccups may cause respiratory alkalosis and are also associated with an increased incidence of ventilator-associated pneumonia. Several pharmacological and nonpharmacological strategies have been devised for the treatment of persistent and intractable hiccups. The evidence to support or declare any intervention as harmful is scarce. In this review, we have presented the pathophysiology and workup, and a stepwise management protocol for intractable hiccups.

Keywords: Hiccups; Intractable hiccups; Neurocritical care; Persistent hiccups; Drug therapy

\section{INTRODUCTION}

Hiccup or hiccough is known by the medical term "singultus," which is a derivative of the Latin word "singult," meaning "a gasp" or "a sob" [1]. Hiccups are characterized by involuntary, intermittent, repetitive, myoclonic, and spasmodic contractions of the diaphragm and the inspiratory intercostal muscles, leading to an abrupt and early closure of the glottis, terminating inspiration and generating the characteristic "hic" sound $[2,3]$. Both healthy adults and children commonly experience hiccup spells. In the fetus, hiccups play a physiological role by training the respiratory muscles for their breathing function, and as a reflex preventing amniotic fluid aspiration $[4,5]$. Transient episodes usually do not require medical attention unlike chronic hiccups (persistent and intractable), which can be associated with long term deleterious effects.

An accurate estimate of the burden of hiccups in the neuro-intensive care unit (ICU) leading to unfavorable outcomes and morbidity is unknown. Though persistent hiccups which are intractable and of neurogenic origin can result in hyperventilation and respiratory alkalosis, and are a risk factor for ventilator associated pneumonia in intubated and mechanically ventilated patients. Hence, meticulous evaluation and treatment of persistent or intractable hiccups $(\mathrm{IH})$ in neuro-ICU patients is important, in a stepwise and protocolized manner which comprise of physical maneuvers first followed by pharmacological measures in failed or 
resistant cases. Unfortunately, there are no clear guidelines applicable to the management of persistent or IH. Recently U.S. Food and Drug Administration (FDA) revoked the approval of chlorpromazine, citing its serious side effects in treating hiccups. In this article we strive to review the available literature on hiccups and provide a stepwise management protocol.

A single episode of hiccups can last from a few seconds to as long as several days. Based on the duration, hiccups can be divided into three categories: acute hiccups that last for up to 48 hours, persistent or protracted hiccups that last for more than 48 hours, and $\mathrm{IH}$ that last for over a month $[6,7]$. Most classifications use arbitrary time limits to categorize the phenomenon. Brief episodes of hiccupping are physiological. The point of transition to a pathological form is not well defined. The longer the duration of the hiccupping, the less amenable it will be to interventions. An episode lasting longer than a week is considered chronic while resistance to sequential therapy using three different drugs warrants the use of the label obstinate [8].

\section{EPIDEMIOLOGY}

Hiccups are more common in diseases affecting the gastrointestinal or central nervous system (CNS). Gender differences in hiccups frequency have not been seen in healthy subjects. Prevalence of non-CNS origin hiccups is higher in men than CNS origin hiccups $[9,10]$. No racial, geographic, or socioeconomic variation in hiccups has been documented. Recurrent hiccups occur in about $3 \%$ of the healthy population, compared to approximately $20 \%$ with Parkinson disease and $10 \%$ of patients with gastroesophageal reflux disease (GERD) [11]. Overall, the prevalence of hiccups in advanced cancer has been reported to be $3.9 \%-4.8 \%[12,13]$. A variety of CNS pathologies cause IH. Lateral medullary infarcts (LMIs) cause $12 \%-36 \%$ of central hiccups cases. Keane (1961) found $56 \%$ of patients with central hiccups to primarily have LMIs, [14] and this proportion was $14 \%$ as per the report by Park et al. [15]. There is high preponderance of developing IH following an ischemic insult to the brainstem including pons or involvement of posterior inferior cerebellar artery [16,17]. Vascular lesions of CNS are the most common cause of IH followed by infective (meningitis, encephalitis), structural lesions, such as a multitude of space occupying lesions like cavernous angiomas or tuberculomas, and inflammatory and demyelinating conditions such as multiple sclerosis and neuromyelitis optica [18].

\section{PATHOPHYSIOLOGY}

The mechanism of hiccups is not very clear and the neuroana- tomical center for hiccups has not been identified, though few hiccups provoking hypothesis have been proposed $[19,20]$. Bailey [21] first proposed the "reflex arc" in 1943 responsible for generating hiccups. The afferent impulse in this proposed arc is carried by the vagus nerve, phrenic nerves, or sympathetic nerve fibers (thoracic outflow T6-T12). Upper spinal cord (C3-C5), medulla oblongata near the respiratory centers, the reticular formation, and the hypothalamus appear to be the CNS centers involved in the hiccup response. Dopaminergic and gamma-aminobutyric acid (GABA)ergic neurotransmitters are involved in the modulation of this central mechanism [22]. The efferent response of the reflex is carried by the phrenic nerve to the diaphragm. Accessory nerves activation lead to the contraction of the intercostal muscles as well. Recurrent laryngeal nerve causes the reflex closure of the glottis, completing the sequence of events during a hiccup [22,23]. Davis concluded that hiccup generation was a supraspinal mechanism involving interplay between behavioral and chemical respiratory influences at the spinal level, independent of inspiratory centers [24]. Suppression of inhibitory influences on a supraspinal hiccup center could lower the threshold and cause hiccups to start. This mechanism may explain the persistent hiccups seen in multiple sclerosis or metabolic disorders. Hassler [25] propounded that hiccups may be generated at the pontomedullary level of the triangle of Guillain-Mollaret (inferior olivary nucleus, dentate nucleus, and red nucleus). Denervation super sensitivity of the inferior olivary complex, nucleus ambiguus, and adjacent reticular formation of medullary oblongata have also been hypothesized to give rise to hiccups [26-28]. Nucleus raphe magnus with its GABA-containing inhibitory cells has been shown to be the likely source of inhibitory inputs to the hiccup reflex arc [29]. Various neurotransmitter pathways of the brainstem and medulla, including those involving dopamine, serotonin, opioids, calcium channels, and GABA are possibly involved in mediating hiccups [30] (Fig. 1).

\section{ETIOLOGY}

Any process that affects the peripheral afferent, central, or efferent components of the proposed reflex arc can trigger hiccups [22]. The most common benign reason being large meals or carbonated drinks causing stomach distension. Hot and spicy foods, alcohol, smoking, and other substances irritating the gastrointestinal or pulmonary tracts can also trigger the reflex. Over-excitement or anxiety, when accompanied by hyperventilation or air swallowing (aerophagia) can trigger hiccups as well.

The causes of persistent hiccups can be classified into central and peripheral (Table 1). Central hiccups could occur with any le- 
Table 1. Causes of hiccups

\begin{tabular}{ll}
\hline Cause of hiccups & \\
$\begin{array}{l}\text { 1. Central nervous system lesion } \\
\text { Vascular pathology }\end{array}$ & Stroke, infarct, aneurysms \\
Neoplasm & Astrocytoma, cavernoma, brain stem tumors \\
Inflammation & Neuromyelitis optica, multiple sclerosis \\
Trauma & Traumatic brain injury \\
Infection & Encephalitis, meningitis \\
2. Peripheral cause & Mediastinal lesions, diaphragmatic tumors \\
Thoracic & Ischemic heart disease, pericarditis, thoracic aneurysm \\
Heart & Gastroesophageal reflux disease, Helicobacter pylori infection, esophageal tumors \\
Gastrointestinal tract & Bronchitis, pneumonia, tuberculosis, asthma \\
Pulmonary & Ascites, intestinal obstruction, pelvic tumors \\
Miscellaneous & Bronchoscopy, tracheostomy, thoracic or abdominal surgeries, central venous catheterization \\
3. Surgical & Chemotherapy, anti-Parkinsonian drugs, dexamethasone, opioids, benzodiazepines, macrolides, anti-psychotic \\
4. Drug induced & medications \\
& Anxiety, stress, fear, excitement \\
5. Psychosomatic &
\end{tabular}

sions along the pathway from the CNS to the phrenic nerve, especially with lesions of the brain stem, such as tumors and ischemic stroke $[15,17,18,31]$. Peripheral hiccups can be caused by diseases at the phrenic nerve level involving diaphragmatic irritation, such as gastric distention, subdiaphragmatic abscess, or hepatosplenomegaly.

\section{CNS lesions}

The dorsal area of the medulla is commonly associated with hiccups as it incorporates a number of complex structures which conciliate the reflex arc, including the vagus nerve, respiratory center, solitary nucleus, nucleus ambiguus, central sympathetic tract, and spinal tract of trigeminal nucleus. Chronic hiccups have been reported following hemorrhagic and ischemic strokes, cerebellar aneurysms, and neuromyelitis optica [32-38].

\section{Peripheral nervous system lesions}

Involvement of the hiccup reflex arc in conditions like sarcoidosis, diaphragm tumors, or other causes of abdominal distension may lead to persistent hiccups.

\section{Gastrointestinal and abdominal causes}

GERD is commonly associated with persistent hiccups and is responsive to treatment with proton pump inhibitors $[39,40]$. Helicobacter pylori infection may lead to persistent hiccups secondary to increased acid production causing irritation of esophageal vagal afferents [41].

\section{Hiccups under anesthesia}

Hiccups can occur during administration of general or regional anesthesia [42], particularly under lighter plane of anesthesia especially with the usage of short acting barbiturates and during intubation, patient positioning, or visceral manipulation during surgery. Surgeries in thorax and abdomen often lead to hiccups in the postoperative period probably due to gastroparesis [43]. Anesthetic drugs like propofol induced hiccups [44]. Hiccups following epidural anesthesia have been reported with possible mechanism of action being deafferentation of sensory nerves in the viscera coupled with increased diaphragmatic stimulation secondary to interruption of phrenic nerve motor reflex $[45,46]$.

\section{Cancer patients}

Hiccups are frequently seen in patients with cancer either due to involvement of any portion of the hiccup reflex arc by the tumor, or as a secondary response to chemotherapy. Cisplatin is most commonly implicated [47].

\section{Drug-induced hiccups}

Steroids have been implicated in chronic hiccups. Dopamine agonists may induce bouts of hiccups in Parkinsonism patients owing to their high affinity towards D3 receptors. Macrolides like azithromycin and psychiatric medications like aripiprazole have also been known to be associated with persistent hiccups. In essence, it is imperative to thoroughly review the medication history and identify and stop the offending drugs inducing hiccups [48]. 


\section{Instrumentation-associated hiccups}

Atrial pacing, catheter ablation of atrial fibrillation, and central venous catheter placement have been reported to cause hiccups presumably due to mechanical irritation of right phrenic nerve which is in close proximity to the right atrium [49-51]. Esophageal instrumentations like stenting induces hiccup by stimulating the reflex arc afferent component [52].

\section{Psychogenic causes}

Hiccups are seen in patients with acute anxiety, stress, fear, or excitement. In cases where behavioral therapy has been successful in ameliorating hiccups, a diagnosis of hysterical hiccups has been made [53].

\section{Miscellaneous causes}

Dyselectrolytemias, tuberculosis, ethanol abusers, diabetes mellitus, and chronic renal failure (due to uremia) [54] can all cause persistent hiccups. Electroencephalogram findings in patients with epilepsy suggest that chronic hiccup can be the result of seizure activity. Certain antiepileptic drugs have shown a beneficial role in the treatment of hiccups mainly due to their GABAergic effects. However, in many patients, chronic hiccups occur without the presence of cerebral dysfunction and diazepam, a potent anti-convulsant drug, can precipitate or exacerbate hiccups in such conditions $[55]$.

\section{EFFECTS OF PERSISTENT HICCUPS}

Persistent hiccups have the capacity to induce major disabling impact on general health and cause exhaustion, sleep deprivation, malnutrition, dehydration, depression, wound dehiscence, and even death in extreme cases [2,56]. It has a detrimental effect on rehabilitation as shown by prolonged hospital stay in a study done by Kumar and Dromerick [16]. Sleep cycle is affected by hiccups with literature showing that it persists during sleep disrupting both non-rapid eye movement (NREM) and REM sleep. Chronic hiccups lead to sleep deprivation [57].

\section{EFFECTS OF HICCUPS ON RESPIRATION}

The occurrence of hiccups in a patient receiving mechanical ventilation causes desynchronization and possible respiratory alkalosis leading to lung damage and hemodynamic alterations [58]. It can be prevented by close monitoring of respiratory parameters and prompt correction, especially in patients with brain stem damage. The strong inspiratory effort does not result in a large change in lung volume due to reflex glottic closure, and, therefore, in normal subjects the ventilatory effects of hiccups are minimal. In intubated or tracheostomized patients, hyperventilation and respiratory alkalosis may happen resulting in hiccups [59].

Marinella [2] were able to demonstrate that the left hemi-diaphragm was the side of hiccup origin in $80 \%$ of their cohort of patients with advanced malignancy. Persistent and $\mathrm{IH}$ are a risk factor for ventilator-associated pneumonia in intubated patients. Employing continuous positive airway pressure and pressure support ventilation can stop hiccups in such patients. Salem et al. [60] demonstrated that increasing PIP to $30-40 \mathrm{cmH}_{2} \mathrm{O}$ immediately stopped the development of hiccup during a surgical procedure.

\section{EVALUATION}

A thorough and detailed history is warranted focusing on trigger factors for chronic hiccups along with frequency, duration, progression, and aggravating and relieving factors. Relevant history should be elicited regarding the chronology of hiccup episodes, relationship with sleep, and any physical maneuver or pharmacological treatment the patient is undergoing with their effectiveness on the condition and any side effects experienced. A comprehensive enquiry should be made regarding the prescribed medications the patient has been administered along with over-thecounter medications and various addictive habits, such as smoking and alcohol consumption. An underlying organic pathology should be ruled out in patients with chronic hiccups.

A detailed physical examination should be done along with a systemic one focusing on the respiratory, nervous, and gastrointestinal systems. An electrocardiogram may help rule out atypical myocardial infarction especially in the beginning of a hiccup attack. Routine blood workup should be done including complete blood count, electrolytes, blood urea nitrogen, creatinine, calcium, liver function tests, and amylase/lipase. Investigation to rule out GERD is important and includes an upper gastrointestinal endoscopy, esophageal manometry, and a 24 hour-pH-impedance reflux study [61]. In patients where no organic cause can be found or those not responding to routine treatment, imaging studies like computed tomography scan and magnetic resonance imaging of head and neck are warranted [62]. Stepwise management protocol is given in flow diagram (Fig. 2).

\section{TREATMENT}

The treatment approach of persistent hiccups is mostly based on observational reports and case series, and clear-cut guidelines are lacking. The treatment is mainly directed at treating the underlying cause when the illness causing hiccups has been identified 


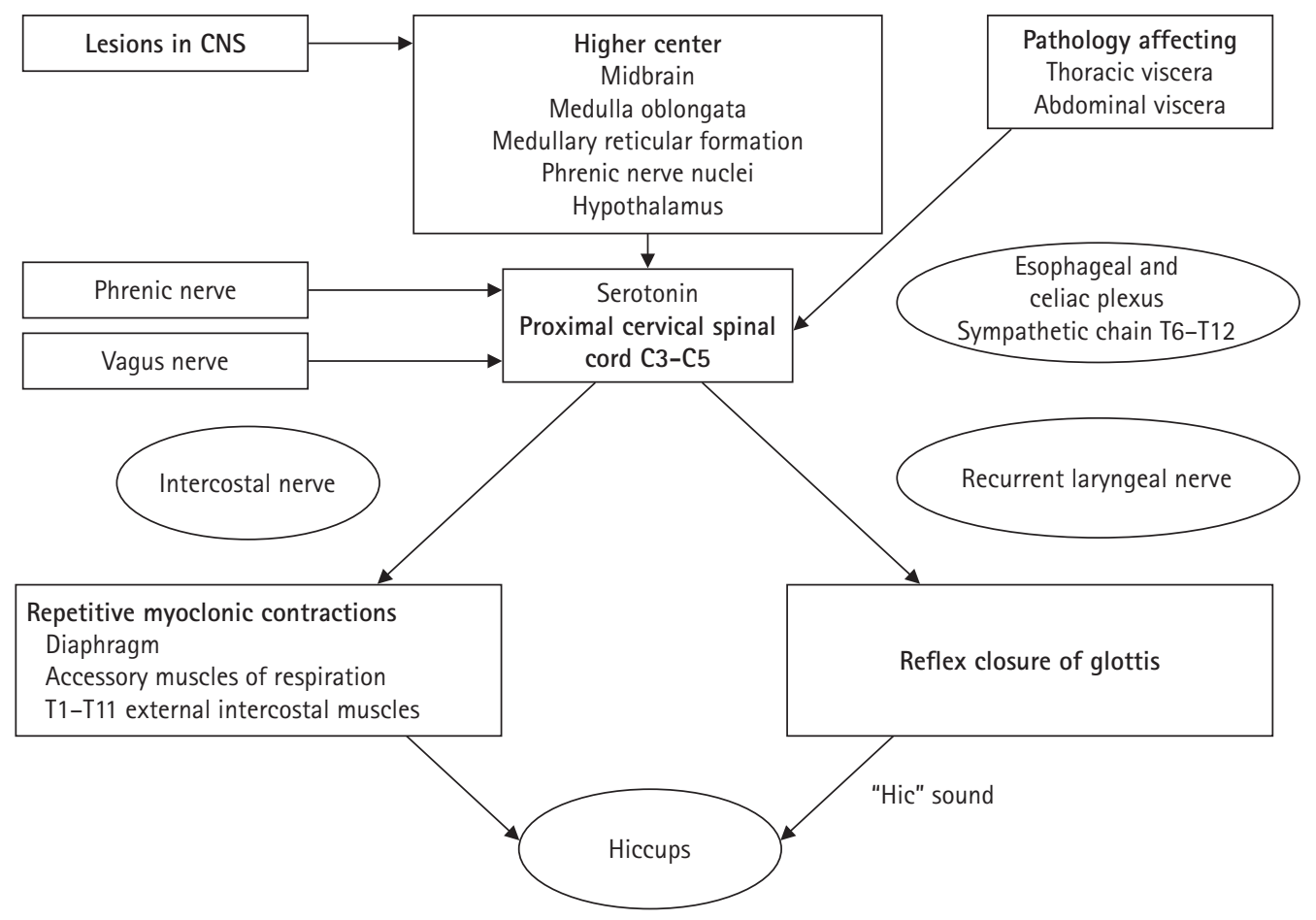

Fig. 1. Hiccup reflex arc. Activation of "hiccup center" by lesions in the central nervous system (CNS) or periphery triggers hiccups mediated via phrenic and intercostal nerves, leading to myoclonic repetitive contractions of the diaphragm and accessory muscles. The characteristic "hic" sound is produced due to reflex closure of the glottis via recurrent laryngeal nerve.

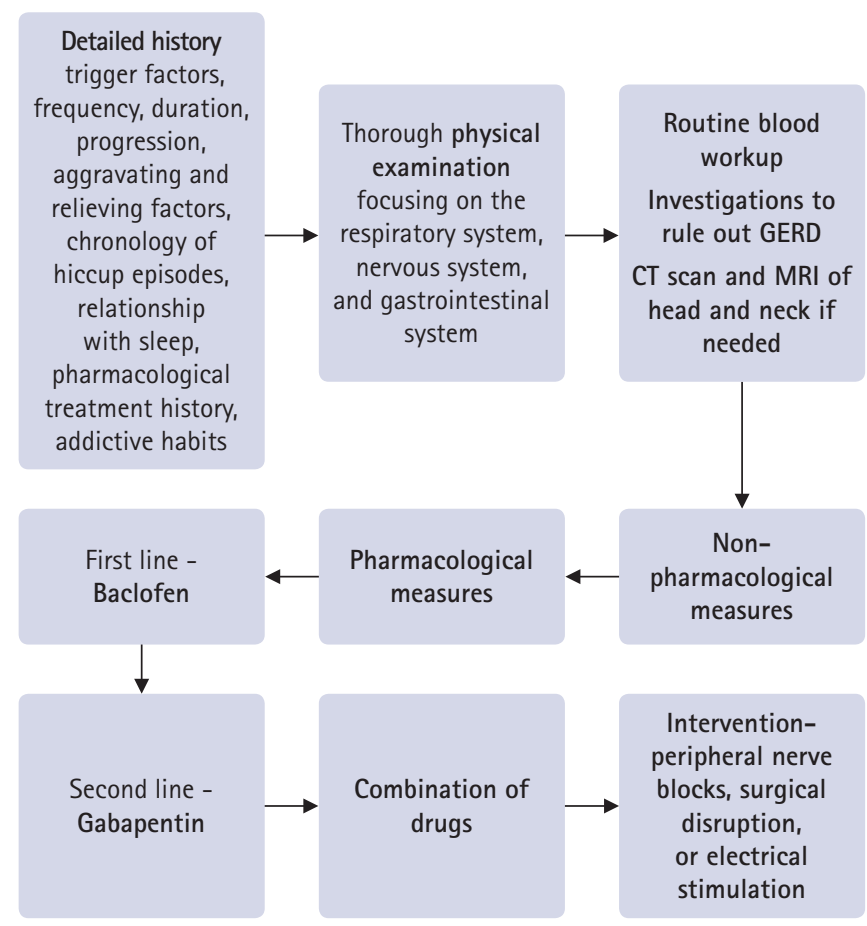

Fig. 2. Stepwise management protocol. GERD, gastroesophageal reflux disease; $\mathrm{CT}$, computed tomography; MRI, magnetic resonance imaging.
$[2,22,23]$. In majority of the cases, no cause is found and the treatment is mainly empirical to ameliorate the symptoms. Table 2 shows the anecdotal and nonpharmacological treatment methods. Physical maneuvers such as interrupting normal respiratory function (e.g., breath holding, Valsalva maneuver), stimulating nasopharynx or uvula (e.g., sipping cold water, gargling with water, swallowing a teaspoon of dry sugar), increasing vagal stimulation (e.g., pressing on the eyeballs), and countering irritation of the diaphragm (e.g., pulling knees to chest, leaning forward to compress the chest) are first-line treatments for hiccups. The basic principle of the various physical maneuvers employed is to interrupt or suppress the reflex arc [7]. These, at best, provide a transient relief in cases of persistent or IH. Drug therapy should be reserved for treatment of hiccups when physical maneuvers have failed $[63,64]$.

\section{Pharmacological}

There is inadequate data to formulate treatment guidelines for persistent hiccups [57]. A complete medical history regarding the ongoing medications and comorbid conditions should be available, and the possible drug interactions and probable side effects should be kept in mind before the choice of medication is made. Combination therapy for $\mathrm{IH}$ has also been proposed in certain case reports [65]. The drug therapy could be tapered out or dis- 
continued if hiccups cease, and alternative drug or treatment modality could be considered in case of IH. The pharmacological treatment is summarized in Table 3.

\section{Chlorpromazine}

Chlorpromazine, a dimethylamine derivative of phenothiazine, is a centrally acting dopamine antagonist which acts at the hypothalamus. The concerns pertaining to long-term neurological side effects along with hypotension, urinary retention, glaucoma, or delirium associated with the use of chlorpromazine has led to its U.S. FDA approval recently being withdrawn. The suggested dose has been 10-25 mg orally or intravenously; if no response then up to 25-50 mg three times a day can be used [66]. Other neuroleptics, like haloperidol or olanzapine, though effective are limited by their untoward effects such as such as dizziness, mood disturbance, and sedation.

\section{Haloperidol}

It alleviates hiccups by its dopamine antagonism in the hypothalamus. The major side effect is extrapyramidal symptoms. Recommended dosage is $5-10 \mathrm{mg} /$ day orally or $2 \mathrm{mg}$ intramuscularly [67].

\section{Olanzapine}

Postsynaptic serotonergic receptors augment phrenic motoneuronal activity and play a role in the generation of hiccups. Olanzapine is proposed to act as an antagonist at these postsynaptic receptors, thereby, attenuates phrenic excitability and relieves hiccups. Alderfer and Arciniegas [68] reported that a maintenance dose of $2.5 \mathrm{mg}$ once daily led to remission of IH secondary to brain injury.

\section{Benzodiazepines}

High-dose benzodiazepines can alleviate treatment-resistant hiccups by suppressing the repetitive, myoclonic contractions of the diaphragm. Midazolam is used via continuous infusion at the rate of $10-60 \mathrm{mg} / 24 \mathrm{hr}$ in patients with terminal hiccups, in the context of refractory delirium or agitation [69].

\section{Muscle relaxants}

\section{Baclofen}

Baclofen, a GABA-B agonist, inhibits transient relaxations of the lower esophageal sphincter and diaphragm with its peripherally and centrally mediated effect on vagal nerves. It also affects the esophago-gastric junction and suppresses reflux after meals. Concerns with its use include ataxia, confusion, and sedation especially in elderly patients with renal failure. Dose is $5 \mathrm{mg}$ per 12 or 8 hours to start with, progressively increased by $15 \mathrm{mg}$ every 3 days to a maximum daily dosage of $75 \mathrm{mg}$ till optimal dose is reached [70-72]. Treatment should be slowly tapered over several days and never abruptly stopped.

\section{Anti-epileptic drugs}

Anti-convulsant medications are used as a second line treatment of persistent hiccups. They block the excitatory neural sodium channels (e.g., phenytoin, carbamazepine), enhance the release of GABA, and decrease the release of excitatory neurotransmitters in the CNS.

\section{Gabapentin}

Gabapentin modulates diaphragmatic excitability by increasing the endogenous GABA-mediated inhibition of inspiratory muscles and reducing calcium influx through inhibitory effects on voltage-operated calcium channels in the presynaptic terminals of respiratory muscles. It also increases serotonin levels in the nucleus raphe magnus of the medulla, which is the most likely source of GABAergic inhibitory inputs to the hiccup reflex arc. Gabapentin either alone or in combination with other medications has been

Table 2. Anecdotal and nonpharmacological treatment methods

\begin{tabular}{lc}
\hline Treatment & Method \\
\hline Anecdotal treatments [52] & $\begin{array}{c}\text { Fast drinking of a large glass of water, application of ice on epigastrium, nasal and pharyngeal } \\
\text { stimulation, pressure on bridge of nose, gargling with water, carbonated beverages, swallowing } \\
\text { granulated sugar or crushed ice, massage of hard/soft palate junction, digital rectal examination } \\
\text { acupuncture, meditation, bilateral pressure on external auditory meatus }\end{array}$ \\
$\begin{array}{l}\text { Nonpharmacological treatment of hiccup [45] } \\
\text { Respiratory maneuver }\end{array}$ & $\begin{array}{l}\text { Breath holding with neck extended, coughing, Valsalva maneuver, rebreathing in a bag, } \\
\text { compression of the diaphragm by drawing legs up or leaning forward, compression of thyroid } \\
\text { cartilage } \\
\text { Bsychiatric treatment } \\
\text { Bastric distension relief }\end{array}$ \\
Phrenic nerve disruption & $\begin{array}{c}\text { Fasting for } 24 \text { hours, gastric aspiration, lavage, induced vomiting, pulling out Ryle's tube by few } \\
\text { centimeters } \\
\text { Local anesthetic injection, compression of phrenic nerve at the neck, phrenic nerve stimulation }\end{array}$
\end{tabular}


Table 3. Summary of pharmacological treatment

\begin{tabular}{|c|c|c|c|}
\hline Drug & Action mechanism & Recommended dose & Considerable side effect \\
\hline Chlorpromazine [66] & $\begin{array}{l}\text { Dopamine antagonist that acts at the } \\
\text { hypothalamus }\end{array}$ & $\begin{array}{l}\text { 10-25 mg orally or intravenously } \\
\text { Max: } 25-50 \mathrm{mg} \text { three times a day }\end{array}$ & $\begin{array}{l}\text { Hypotension, urinary retention, } \\
\text { glaucoma, or delirium }\end{array}$ \\
\hline Haloperidol [67] & $\begin{array}{l}\text { Dopamine antagonism in the } \\
\text { hypothalamus }\end{array}$ & $\begin{array}{l}\text { 5-10 mg/day orally or } 2 \mathrm{mg} / \text { day } \\
\text { intramuscularly }\end{array}$ & $\begin{array}{l}\text { Extrapyramidal symptoms, dizziness, } \\
\text { mood disturbance, and sedation }\end{array}$ \\
\hline Olanzapine [68] & $\begin{array}{l}\text { Postsynaptic serotonergic receptors } \\
\text { antagonist, attenuates phrenic } \\
\text { excitability }\end{array}$ & $2.5 \mathrm{mg}$ once daily & $\begin{array}{l}\text { Dizziness, mood disturbance, and } \\
\text { sedation }\end{array}$ \\
\hline Benzodiazepines [69] & $\begin{array}{l}\text { In high doses suppresses the repetitive, } \\
\text { myoclonic contractions of the } \\
\text { diaphragm }\end{array}$ & $\begin{array}{l}\text { Midazolam: continuous infusion at the } \\
\text { rate of } 10-60 \mathrm{mg} / 24 \mathrm{hr} \text { in patients } \\
\text { with terminally hiccups in the context } \\
\text { of refractory delirium or agitation }\end{array}$ & Sedation, respiratory depression \\
\hline \multicolumn{4}{|l|}{ Muscle relaxant } \\
\hline Baclofen [70-72] & GABA-B agonist & $\begin{array}{l}5 \mathrm{mg} \text { per } 12 \text { or } 8 \text { hours to start with, } \\
\text { and progressively increased by } 15 \\
\text { mg every } 3 \text { days to a maximum daily } \\
\text { dosage of } 75 \mathrm{mg}\end{array}$ & $\begin{array}{l}\text { Ataxia, confusion, and sedation } \\
\text { especially in elderly patients with } \\
\text { renal failure }\end{array}$ \\
\hline \multicolumn{4}{|l|}{ Anti-epileptic drug } \\
\hline Gabapentin [73] & $\begin{array}{l}\text { Increasing the endogenous } \\
\text { GABA-mediated inhibition modulates } \\
\text { diaphragmatic excitability }\end{array}$ & $\begin{array}{l}300 \mathrm{mg} \text { three times daily orally and } \\
\text { titrated according to response, or } 400 \\
\mathrm{mg} \text { three times daily for } 3 \text { days, then } \\
400 \mathrm{mg} \text { once daily for } 3 \text { days and then } \\
\text { stopped. }\end{array}$ & \\
\hline Carbamazepine [74] & & 200 mg every 6 hours given orally & \\
\hline Valproic acid [75] & $\begin{array}{l}\text { Increases the GABA transmission } \\
\text { centrally }\end{array}$ & $\begin{array}{l}200-500 \mathrm{mg} \text { orally }(15 \mathrm{mg} / \mathrm{kg} / 24 \mathrm{hr} \text { in } \\
\text { divided doses) }\end{array}$ & $\begin{array}{l}\text { Gastrointestinal bleeding and hepatic } \\
\text { toxicity }\end{array}$ \\
\hline \multicolumn{4}{|l|}{ Others } \\
\hline Metoclopramide $[76,77]$ & $\begin{array}{l}\text { D3 antagonist and 5-HT4 agonist; } \\
\text { central anti-emetic and peripheral } \\
\text { prokinetic properties with lower } \\
\text { esophageal sphincter tightening effect }\end{array}$ & $\begin{array}{l}10 \mathrm{mg} \text { intravenously three to four times } \\
\text { a day }\end{array}$ & Tardive dyskinesia \\
\hline Domperidone [65] & Dopamine antagonist & $10 \mathrm{mg}$ three to four times a day & $\begin{array}{l}\text { QT interval prolongation, cardiac } \\
\text { dysrhythmias }\end{array}$ \\
\hline Cisapride [78] & 5-HT4 agonism & $10 \mathrm{mg}$ three times a day orally & Insomnia, anxiety, nervousness \\
\hline Nifedipine [79] & $\begin{array}{l}\text { Calcium channel blocker; interrupts the } \\
\text { reflex arc by reversing the abnormal } \\
\text { depolarization }\end{array}$ & $\begin{array}{l}10 \text { mg orally three times a day with } \\
\text { concurrent fludrocortisone } 0.5-1 \mathrm{mg} \\
\text { orally }\end{array}$ & Hypotension \\
\hline Methylphenidate [80] & $\begin{array}{l}\text { Inhibition of dopamine and } \\
\text { norepinephrine reuptake }\end{array}$ & $\begin{array}{l}5 \mathrm{mg} \text { orally (maintenance } 5-10 \mathrm{mg} \\
\text { twice daily) }\end{array}$ & $\begin{array}{l}\text { Insomnia, increased blood pressure, } \\
\text { headache, nervousness }\end{array}$ \\
\hline Nefopam [81] & Dopamine antagonist & $\begin{array}{l}0.25 \mathrm{mg} / \mathrm{kg} \text { over } 10 \mathrm{sec} \text { intravenously } \\
\text { (10 mg intravenously four times daily } \\
\text { for } 2 \text { days) }\end{array}$ & $\begin{array}{l}\text { Dizziness, light headedness, } \\
\text { hallucinations, nervousness, } \\
\text { confusion, pink discoloration of urine }\end{array}$ \\
\hline Carvedilol [82] & $\begin{array}{l}\text { Acts on the afferent sympathetic } \\
\text { component of the reflex arc }\end{array}$ & $6.25 \mathrm{mg}$ four times daily & $\begin{array}{l}\text { Dizziness, light headedness, shortness } \\
\text { of breath, slow heartbeat }\end{array}$ \\
\hline Lidocaine [83-85] & Effect on the irritant sensory afferents & $\begin{array}{l}1 \mathrm{mg} / \mathrm{kg} \text { loading dose followed by } \\
\text { infusion of } 2 \mathrm{mg} / \mathrm{min} \\
3 \mathrm{~cm}^{3} \text { of } 4 \% \text { topical lidocaine nebulized } \\
\text { in a standard small-particle nebulize }\end{array}$ & $\begin{array}{l}\text { Neurological and cardiovascular } \\
\text { toxicities with intravenous drug; } \\
\text { short-term loss of the gag reflex } \\
\text { with nebulized drug }\end{array}$ \\
\hline Amantadine [86] & $\begin{array}{l}\text { N-methyl-D-aspartate subtype of } \\
\text { glutamate receptors antagonist, } \\
\text { anticholinergic activity }\end{array}$ & 100 mg once daily & $\begin{array}{l}\text { Dizziness, light headedness, dry } \\
\text { mouth, constipation, insomnia }\end{array}$ \\
\hline
\end{tabular}

GABA, gamma-aminobutyric acid.

recommended especially in patients with hiccups secondary to brain tumors. Gabapentin dosage is $300 \mathrm{mg}$ three times daily orally and titrated according to response, or $400 \mathrm{mg}$ three times daily for 3 days, then $400 \mathrm{mg}$ once daily for 3 days, and then stopped [73]. Porzio et al. [12] in their retrospective study evaluated gab- apentin's efficacy in patients with advanced cancer having severe chronic hiccups and concluded that gabapentin can be used as a next line therapy to chlorpromazine. It has a favorable side effect profile compared to other anti-epileptic drugs. 


\section{Carbamazepine}

The recommended dosage of carbamazepine is $200 \mathrm{mg}$ every 6 hours taken orally [74].

\section{Valproic acid}

Valproic acid increases the GABA transmission centrally and interrupts the hiccup stimuli. It is associated with serious side effects like gastrointestinal bleeding and hepatic toxicity. Recommended dosage is $200-500 \mathrm{mg}$ orally ( $15 \mathrm{mg} / \mathrm{kg} / 24 \mathrm{hr}$ in divided doses) [75].

\section{Metoclopramide}

It is a D3 antagonist and 5-HT4 agonist with a chemical structure similar to neuroleptic drugs. It has both central anti-emetic and peripheral prokinetic properties with a lower esophageal sphincter tightening effect. Its efficacy in hiccups is due to gastric emptying because of its prokinetic property, which reduces gastric distension and GERD. Recommended dose is $10 \mathrm{mg}$ intravenously three to four times a day [76,77]. Wang and Wang [77] in their randomized study demonstrated its benefit on terminating hiccups. Long-term dosing is associated with risk of tardive dyskinesia.

\section{Domperidone}

The drug is devoid of neurological side effects associated with metoclopramide as it does not cross the blood-brain barrier. It has a better risk profile over a longer period of time but there are concerns with its propensity to cause QT interval prolongation and cardiac dysrhythmias. The dosage is $10 \mathrm{mg}$ three to four times a day [65].

\section{Cisapride}

It has 5-HT4 agonism and an effect comparable to metoclopramide. Dosage is $10 \mathrm{mg}$ three times a day, taken orally [78].

\section{Nifedipine}

It is a calcium channel blocker and interrupts the reflex arc by reversing the abnormal depolarization, with the major side effect being hypotension. Recommended dosage is $10 \mathrm{mg}$ orally three times a day with concurrent fludrocortisone $0.5-1 \mathrm{mg}$ orally [79].

\section{Methylphenidate}

It terminates hiccups through inhibition of dopamine and norepinephrine reuptake. In the case report published by Maréchal et al. [80], methylphenidate was effective in terminating hiccups in a patient with metastatic small cell lung cancer with a dose of $5 \mathrm{mg}$ orally (maintenance 5-10 mg twice daily).

\section{Nefopam}

It is a non-opioid analgesic with reported efficacy in terminating refractory hiccups with intravenous medication at a dose of 0.25 $\mathrm{mg} / \mathrm{kg}$ over 10 seconds (10 mg intravenously four times daily for 2 days) [81].

\section{Carvedilol}

Carvedilol suppresses hiccups by acting on the afferent sympathetic component of the reflex arc. Stueber and Swartz [82] reported that it was effective in treating hiccups in a patient with tardive dyskinesia and compulsive self-induced hiccups and vomiting, at doses of $6.25 \mathrm{mg}$ four times daily.

\section{Lidocaine}

Lidocaine nebulization is found to be effective in treating hiccups due to its effect on irritant sensory afferents. The safety profile with this is considerably better as compared to intravenous route which is fraught with neurological and cardiovascular toxicities $[83,84]$. Kaneishi and Kawabata [85] reported a case of hiccups, resistant to haloperidol, effectively treated by lignocaine.

\section{Amantadine}

Amantadine is an antagonist at the NMDA receptors with anticholinergic activity and anti-Parkinsonian effect and possible anti-hiccup action. There are case reports regarding the onset of hiccups following administration of dopamine agonists in a patient with Parkinson disease [86].

\section{Combination therapy for $\mathrm{IH}$}

Combination therapy for $\mathrm{IH}$ has also been proposed in certain case reports [65].

\section{Cisapride, omeprazole, and baclofen (COB)}

Petroianu et al. [87] studied oral treatment with cisapride $10 \mathrm{mg}$ three times daily, omeprazole $20 \mathrm{mg}$ once daily, and baclofen 15 mg three times daily in patients with $\mathrm{IH}$ and concluded that $\mathrm{COB}$ is an effective empirical therapy.

\section{Cisapride, omeprazole, baclofen, and gabapentin}

In another study, Petroianu et al. [88] proposed that the addition of gabapentin should be considered in patients for better results.

\section{CONCLUSION}

Hiccups are usually innocuous and frequently ignored. Patients presenting with chronic hiccups require a meticulous evaluation focusing on history and physical examination. Persistent hiccups 
are more often than not associated with an underlying organic pathology which requires a comprehensive workup. Pharmacological therapy should take into account the risk of long-term side effects and FDA recommendations. Considering the present literature on hiccup pharmacotherapy, baclofen may be considered as a first line therapy followed by gabapentin. Large multicenter trials are the need of the hour along with the development of robust guidelines.

\section{ARTICLE INFORMATION}

\section{Ethics statement}

Not applicable.

\section{Conflict of interest}

No potential conflict of interest relevant to this article.

\section{ORCID}

Vanitha Rajagopalan

Deep Sengupta

https://orcid.org/0000-0002-0765-2306

Keshav Goyal https://orcid.org/0000-0002-5183-9223

Surya Kumar Dube https://orcid.org/0000-0001-9139-0689 https://orcid.org/0000-0002-0224-360X

Ashish Bindra https://orcid.org/0000-0001-5685-2833

\section{Author contributions}

Conceptualization: KG, VR, DS. Data curation, Formal analysis, Methodology, Project administration, Visualization, \& Writing original draft: VR, DS, KG. Writing-review \& editing: all authors.

\section{REFERENCES}

1. Chang FY, Lu CL. Hiccup: mystery, nature and treatment. J Neurogastroenterol Motil 2012;18:123-30.

2. Marinella MA. Diagnosis and management of hiccups in the patient with advanced cancer. J Support Oncol 2009;7:122-7, 130.

3. Wallace AH, Manikkam N, Maxwell F. Seizures and a hiccup in the diagnosis. J Paediatr Child Health 2004;40:707-8.

4. Cymet TC. Retrospective analysis of hiccups in patients at a community hospital from 1995-2000. J Natl Med Assoc 2002; 94:480-3.

5. Rey E, Elola-Olaso CM, Rodríguez-Artalejo F, Locke GR 3rd, Díaz-Rubio M. Prevalence of atypical symptoms and their association with typical symptoms of gastroesophageal reflux in Spain. Eur J Gastroenterol Hepatol 2006;18:969-75.

6. Smith HS. Hiccups. In: Walsh TD, editor. Palliative medicine. 1st ed. Philadelphia, PA: Elsevier Saunders; 2009.
7. Kolodzik PW, Eilers MA. Hiccups (singultus): review and approach to management. Ann Emerg Med 1991;20:565-73.

8. Becker DE. Nausea, vomiting, and hiccups: a review of mechanisms and treatment. Anesth Prog 2010;57:150-6.

9. Lee GW, Kim RB, Go SI, Cho HS, Lee SJ, Hui D, et al. Gender differences in hiccup patients: analysis of published case reports and case-control studies. J Pain Symptom Manage 2016; 51:278-83.

10. Souadjian JV, Cain JC. Intractable hiccup: etiologic factors in 220 cases. Postgrad Med 1968;43:72-7.

11. Khorakiwala T, Arain R, Mulsow J, Walsh TN. Hiccups: an unrecognized symptom of esophageal cancer? Am J Gastroenterol 2008;103:801.

12. Porzio G, Aielli F, Verna L, Aloisi P, Galletti B, Ficorella C. Gabapentin in the treatment of hiccups in patients with advanced cancer: a 5-year experience. Clin Neuropharmacol 2010;33: 179-80.

13. Menon M. Gabapentin in the treatment of persistent hiccups in advanced malignancy. Indian J Palliat Care 2012;18:138-40.

14. Sampath V, Gowda MR, Vinay HR, Preethi S. Persistent hiccups (singultus) as the presenting symptom of lateral medullary syndrome. Indian J Psychol Med 2014;36:341-3.

15. Park MH, Kim BJ, Koh SB, Park MK, Park KW, Lee DH. Lesional location of lateral medullary infarction presenting hiccups (singultus). J Neurol Neurosurg Psychiatry 2005;76:95-8.

16. Kumar A, Dromerick AW. Intractable hiccups during stroke rehabilitation. Arch Phys Med Rehabil 1998;79:697-9.

17. al Deeb SM, Sharif H, al Moutaery K, Biary N. Intractable hiccup induced by brainstem lesion. J Neurol Sci 1991;103:14450.

18. Chang YY, Wu HS, Tsai TC, Liu JS. Intractable hiccup due to multiple sclerosis: MR imaging of medullary plaque. Can J Neurol Sci 1994;21:271-2.

19. Kahrilas PJ, Shi G. Why do we hiccup? Gut 1997;41:712-3.

20. Regnard C. Hiccup. In: Doyle D, Hanks G, Cherny N, Calman $\mathrm{KC}$, editors. Oxford textbook of palliative medicine. 3rd ed. Oxford: Oxford University Press; 2004. p. 477-9.

21. Bailey H. Persistent Hiccup. Practitioner 1943;150:173-177.

22. Steger M, Schneemann M, Fox M. Systemic review: the pathogenesis and pharmacological treatment of hiccups. Aliment Pharmacol Ther 2015;42:1037-50.

23. Friedman NL. Hiccups: a treatment review. Pharmacotherapy 1996;16:986-95.

24. Davis JN. An experimental study of hiccup. Brain 1970;93:85172.

25. Hassler R. The neural system of extrapyramidal myoclonia and their stereotactic treatment. In: Doose H, editor. Current neuro- 
paediatrics. Stuttgart: Thieme; 1997.p. 20-46.

26. Lapresle J, Hamida MB. The dentato-olivary pathway: somatotopic relationship between the dentate nucleus and the contralateral inferior olive. Arch Neurol 1970;22:135-43.

27. Matsuo F, Ajax ET. Palatal myoclonus and denervation supersensitivity in the central nervous system. Ann Neurol 1979;5: 72-8.

28. Turazzi S, Alexandre A, Bricolo A, Rizzuto N. Opsoclonus and palatal myoclonus during prolonged post-traumatic coma: a clinico-pathologic study. Eur Neurol 1977;15:257-63.

29. Oshima T, Sakamoto M, Tatsuta H, Arita H. GABAergic inhibition of hiccup-like reflex induced by electrical stimulation in medulla of cats. Neurosci Res 1998;30:287-93.

30. Nausheen F, Mohsin H, Lakhan SE. Neurotransmitters in hiccups. Springerplus 2016;5:1357.

31. Fisher CM, Karnes WE, Kubik CS. Lateral medullary infarction: the pattern of vascular occlusion. J Neuropathol Exp Neurol 1961;20:323-79.

32. Kim JS. Pure lateral medullary infarction: clinical-radiological correlation of 130 acute, consecutive patients. Brain 2003; 126(Pt 8):1864-72.

33. Alix JJ, Ponnusamy A, Bhattacharyya D, Hoggard N, Grünewald RA. Complex partial seizures: going out with a hiccup. Seizure 2012;21:820-2.

34 .Musumeci A, Cristofori L, Bricolo A. Persistent hiccup as presenting symptom in medulla oblongata cavernoma: a case report and review of the literature. Clin Neurol Neurosurg 2000; 102:13-7.

35. Lee KH, Moon KS, Jung MY, Jung S. Intractable hiccup as the presenting symptom of cavernous hemangioma in the medulla oblongata: a case report and literature review. J Korean Neurosurg Soc 2014;55:379-82.

36. Weisscher N, Vermeulen M, Roos YB, de Haan RJ. What should be defined as good outcome in stroke trials; a modified Rankin score of 0-1 or 0-2? J Neurol 2008;255:867-74.

37. Gambhir S, Singh A, Maindiratta B, Jaeger M, Darwish B, Sheridan M. Giant PICA aneurysm presenting as intractable hiccups. J Clin Neurosci 2010;17:945-6.

38. Mandaliya R, Boigon M, Smith DG, Bhutani S, Ali N, Hilton C, et al. A diagnostic challenge in a young woman with intractable hiccups and vomiting: a case of neuromyelitis optica. J Community Hosp Intern Med Perspect 2015;5:28850.

39. Gluck M, Pope CE 2nd. Chronic hiccups and gastroesophageal reflux disease: the acid perfusion test as a provocative maneuver. Ann Intern Med 1986;105:219-20.

40. Pooran N, Lee D, Sideridis K. Protracted hiccups due to severe erosive esophagitis: a case series. J Clin Gastroenterol 2006;
40:183-5.

41. Orr CF, Rowe DB. Helicobacter pylori hiccup. Intern Med J 2003;33:133-4.

42. Kranke P, Eberhart LH, Morin AM, Cracknell J, Greim CA, Roewer N. Treatment of hiccup during general anaesthesia or sedation: a qualitative systematic review. Eur J Anaesthesiol 2003;20:239-44.

43. Renes SH, van Geffen GJ, Rettig HC, Gielen MJ, Scheffer GJ. Ultrasound-guided continuous phrenic nerve block for persistent hiccups. Reg Anesth Pain Med 2010;35:455-7.

44. Baraka A. Inhibition of hiccups by the laryngeal mask airway. Anaesthesia 2004;59:926.

45. McAllister RK, McDavid AJ, Meyer TA, Bittenbinder TM. Recurrent persistent hiccups after epidural steroid injection and analgesia with bupivacaine. Anesth Analg 2005;100:1834-6.

46. Andres DW. Transesophageal diaphragmatic pacing for treatment of persistent hiccups. Anesthesiology 2005;102:483.

47. Liaw CC, Wang CH, Chang HK, Wang HM, Huang JS, Lin YC, et al. Cisplatin-related hiccups: male predominance, induction by dexamethasone, and protection against nausea and vomiting. J Pain Symptom Manage 2005;30:359-66.

48. Jover F, Cuadrado JM, Merino J. Possible azithromycin-associated hiccups. J Clin Pharm Ther 2005;30:413-6.

49. Doshi H, Vaidyalingam R, Buchan K. Atrial pacing wires: an uncommon cause of postoperative hiccups. Br J Hosp Med (Lond) 2008;69:534.

50. Sacher F, Monahan KH, Thomas SP, Davidson N, Adragao P, Sanders $\mathrm{P}$, et al. Phrenic nerve injury after atrial fibrillation catheter ablation: characterization and outcome in a multicenter study. J Am Coll Cardiol 2006;47:2498-503.

51. Sav T. Hiccups, a rare complication arising from use of a central venous catheter. Hemodial Int 2010;14:337-8.

52. Turkyilmaz A, Eroglu A. Use of baclofen in the treatment of esophageal stent-related hiccups. Ann Thorac Surg 2008; 85:328-30.

53. Sugimoto T, Takeda N, Yamakawa I, Kawai H, Tanaka Y, Sakaguchi $\mathrm{M}$, et al. Intractable hiccup associated with aseptic meningitis in a patient with systemic lupus erythematosus. Lupus 2008; 17:152-3.

54. Chou CL, Chen CA, Lin SH, Huang HH. Baclofen-induced neurotoxicity in chronic renal failure patients with intractable hiccups. South Med J 2006;99:1308-9.

55. Launois S, Bizec JL, Whitelaw WA, Cabane J, Derenne JP. Hiccup in adults: an overview. Eur Respir J 1993;6:563-75.

56. Moretto EN, Wee B, Wiffen PJ, Murchison AG. Interventions for treating persistent and intractable hiccups in adults. Cochrane Database Syst Rev 2013;2013:CD008768. 
57. Askenasy JJ. Sleep hiccup. Sleep 1988;11:187-94.

58. Byun SH, Jeon YH. Treatment of idiopathic persistent hiccups with positive pressure ventilation: a case report. Korean J Pain 2012;25:105-7.

59. Brouillette RT, Thach BT, Abu-Osba YK, Wilson SL. Hiccups in infants: characteristics and effects on ventilation. J Pediatr 1980;96:219-25.

60. Salem MR, Baraka A, Rattenborg CC, Holaday DA. Treatment of hiccups by pharyngeal stimulation in anesthetized and conscious subjects. JAMA 1967;202:126-30.

61. Cabane J, Bizec JL, Derenne JP. A diseased esophagus is frequently the cause of chronic hiccup: a prospective study of 184 cases. Presse Med 2010;39:e141-6.

62. Ferdinand P, Oke A. Intractable hiccups post stroke: case report and review of the literature. J Neurol Neurophysiol 2012;3:140.

63. Viera AJ, Sullivan SA. Remedies for prolonged hiccups. Am Fam Physician 2001;63:1684-6.

64. Howard RS. Persistent hiccups. BMJ 1992;305:1237-8.

65. Smith HS, Busracamwongs A. Management of hiccups in the palliative care population. Am J Hosp Palliat Care 2003;20:14954.

66. Friedgood CE, Ripstein CB. Chlorpromazine (thorazine) in the treatment of intractable hiccups. J Am Med Assoc 1955;157: 309-10.

67. Ives TJ, Fleming MF, Weart CW, Bloch D. Treatment of intractable hiccups with intramuscular haloperidol. Am J Psychiatry 1985;142:1368-9.

68. Alderfer BS, Arciniegas DB. Treatment of intractable hiccups with olanzapine following recent severe traumatic brain injury. J Neuropsychiatry Clin Neurosci 2006;18:551-2.

69. Wilcock A, Twycross R. Midazolam for intractable hiccup. J Pain Symptom Manage 1996;12:59-61.

70. Ramírez FC, Graham DY. Treatment of intractable hiccup with baclofen: results of a double-blind randomized, controlled, cross-over study. Am J Gastroenterol 1992;87:1789-91.

71. Twycross R. Baclofen for hiccups. Am J Hosp Palliat Care 2003; 20:262.

72. Walker P, Watanabe S, Bruera E. Baclofen, a treatment for chronic hiccup. J Pain Symptom Manage 1998;16:125-32.
73. Tegeler ML, Baumrucker SJ. Gabapentin for intractable hiccups in palliative care. Am J Hosp Palliat Care 2008;25:52-4.

74. McFarling DA, Susac JO. Letter: carbamazepine for hiccoughs. JAMA 1974;230:962.

75. Jacobson PL, Messenheimer JA, Farmer TW. Treatment of intractable hiccups with valproic acid. Neurology 1981;31:145860.

76. Madanagopolan N. Metoclopramide in hiccup. Curr Med Res Opin 1975;3:371-4.

77. Wang T, Wang D. Metoclopramide for patients with intractable hiccups: a multicentre, randomised, controlled pilot study. Intern Med J 2014;44:1205-9.

78. Duffy MC, Edmond H, Campbell K, Fulton JD. Hiccough relief with cisapride. Lancet 1992;340:1223.

79. Mukhopadhyay P, Osman MR, Wajima T, Wallace TI. Nifedipine for intractable hiccups. N Engl J Med 1986;314:1256.

80. Maréchal R, Berghmans T, Sculier P. Successful treatment of intractable hiccup with methylphenidate in a lung cancer patient. Support Care Cancer 2003;11:126-8.

81. Bilotta F, Rosa G. Nefopam for severe hiccups. N Engl J Med 2000;343:1973-4.

82. Stueber D, Swartz CM. Carvedilol suppresses intractable hiccups. J Am Board Fam Med 2006; 19:418-21.

83. Cohen SP, Lubin E, Stojanovic M. Intravenous lidocaine in the treatment of hiccup. South Med J 2001;94:1124-5.

84. Neeno TA, Rosenow EC 3rd. Intractable hiccups: consider nebulized lidocaine. Chest 1996;110:1129-30.

85. Kaneishi K, Kawabata M. Continuous subcutaneous infusion of lidocaine for persistent hiccup in advanced cancer. Palliat Med 2013;27:284-5.

86. Wilcox SK, Garry A, Johnson MJ. Novel use of amantadine: to treat hiccups. J Pain Symptom Manage 2009;38:460-5.

87. Petroianu G, Hein G, Petroianu A, Bergler W, Rüfer R. Idiopathic chronic hiccup: combination therapy with cisapride, omeprazole, and baclofen. Clin Ther 1997;19:1031-8.

88. Petroianu G, Hein G, Stegmeier-Petroianu A, Bergler W, Rüfer R. Gabapentin "add-on therapy" for idiopathic chronic hiccup (ICH). J Clin Gastroenterol 2000;30:321-4. 